\title{
UTILIZAÇÃO DE METODOLOGIAS ATIVAS APOIADAS EM TECNOLOGIAS DIGITAIS PARA O ENSINO DE QUÍMICA: UM RELATO DE EXPERIÊNCIA
}

\author{
USE OF ACTIVE METHODOLOGIES BASED ON DIGITAL TECHNOLOGIES \\ FOR CHEMISTRY TEACHING: AN EXPERIENCE REPORT
}

\section{UTILIZACIÓN DE METODOLOGÍAS ACTIVAS APOYADAS EN TECNOLOGÍAS DIGITALES PARA LA ENSEÑANZA DE QUÍMICA: UN RELATO DE EXPERIENCIA}

\author{
Karla Amâncio Pinto Field’s * (iD) 9 \\ Kátia Dias Ferreira Ribeiro ** (iD) 9 \\ Raquel Aparecida Souza ${ }^{* * *}$ (D) 9
}

\begin{abstract}
RESUMO
O objetivo deste trabalho é apresentar os resultados de uma experiência desenvolvida no componente curricular Química aplicada a serviços de alimentação, do curso Superior de Tecnologia em Gastronomia do Instituto Federal de Brasília - campus Riacho Fundo, na qual foram utilizadas metodologias ativas apoiadas em tecnologias digitais. Escolhemos o relato de experiência para apresentar, discutir e analisar a vivência de uma professora, também autora deste trabalho, que pautou seu planejamento de aulas remotas em um curso de extensão. Os dados foram organizados em cinco experiências com metodologias ativas, a saber: storytelling; storytelling e resolução de problemas; ensino híbrido/sala de aula invertida; aprendizagem em pares; e aprendizagem maker. Os resultados dessa experiência apontam ter havido uma apropriação metodológica por parte da professora, o que é exemplificado pelo planejamento dos roteiros de aprendizagem, conforme proposto a partir das metodologias ativas experienciadas.
\end{abstract}

Palavras-chave: Metodologias ativas. Tecnologias digitais. Prática docente. Ensino de Química.

\begin{abstract}
This study aims at presenting the results of an experience developed in the curricular component Chemistry applied to food services in the Higher Technology Gastronomy course at the Federal Institute of Brasília (IFB) - Riacho Fundo Campus, in which active methodologies supported by digital

\footnotetext{
* Doutora em Química pela Universidade Federal de Goiás (UFG). Docente do Instituto Federal de Educação, Ciência e Tecnologia de Goiás (IFG) em colaboração no IFB campus Riacho Fundo, Brasília, DF. Av. Cedro, AE 15, QS 16 - Riacho Fundo I, Brasília - DF. CEP: 71826-006. E-mail: kapf2@ hotmail.com.

${ }^{* *}$ Doutora em Educação em Ciências e Matemática pela Rede Amazônica de Educação em Ciências e Matemática (REAMEC/UFMT). Docente do Programa de Pós-Graduação em Ensino de Ciências e Matemática (PPGECM) da Universidade Federal de Mato Grosso (UFMT), Sinop, Mato Grosso, Brasil; e do Instituto Federal de Educação, Ciência e Tecnologia (IFMA), Porto Franco, Maranhão, Brasil. Endereço para correspondência: Rua Joaquim Pereira, número 197, Centro, Porto Franco, MA, Brasil, CEP 65970-000. E-mail: katiadfr2@ hotmail.com. **** Doutora em Educação pela Universidade de Brasília (UnB). Docente da Universidade Federal de Uberlândia (UFU) campus Pontal, Ituiutaba, Minas Gerais, Brasil. Rua José Martins Ribeiro, 69, Platina, Ituiutaba, Brasil. CEP: 38307074. E-mail:eraquelas@gmail.com
} 
technologies were used. The experience report was chosen to present, discuss and analyze the experience of a teacher, also the author of this study, who based her lesson plan of online classes on an extension course. The data collected were organized into five experiences with active methodologies such as storytelling; storytelling and problem solving; hybrid teaching / inverted classroom; peer learning; and maker learning. The results of this experience indicate that there was a methodological appropriation by the teacher, which is exemplified by the planning of learning itineraries, as proposed from the experienced active methodologies.

Keywords: Active methodologies. Digital technologies. Teaching practice. Chemistry teaching.

\section{RESUMEN}

El objetivo de este artículo es presentar los resultados de una experiencia desarrollada en la asignatura Química aplicada a los servicios de alimentación del curso Superior de Tecnología en Gastronomía del Instituto Federal de Brasília - Campus Riacho Fundo, en el cual han sido utilizadas metodologías activas apoyadas en tecnologías digitales. Hemos elegido el relato de experiencia para presentar, discutir y analizar la vivencia de una profesora, coautora de este trabajo, que ha hecho su organización pedagógica para las clases remotas en un curso de extensión. Los datos han sido organizados en cinco experiencias con metodologías activas: storytelling; storytelling y resolución de problemas; enseñanza híbrida/clase invertida; aprendizaje en parejas; aprendizaje maker. Los resultados de esa experiencia nos muestran que hubo una apropiación metodológica por parte de la profesora, lo que podemos comprobar a partir de la organización pedagógica de sus guiones de aprendizaje, que han sido construidos de acuerdo con lo propuesto utilizando las metodologías activas experimentadas.

Palabras clave: Metodologías activas. Tecnologías digitales. Práctica docente. Enseñanza de Química.

\section{INTRODUÇÃO}

No início do ano de 2020, por conta da pandemia da COVID-19, doença causada pelo novo coronavírus (SARS-Cov-2), as pessoas em todo o mundo foram conduzidas ao isolamento social como forma de diminuir a propagação do vírus. Para atender a essa necessidade, foram suspensas as atividades escolares presenciais e, com isso, a maioria das instituições educacionais deu início a um movimento de preparação para atendimento aos alunos e prosseguimento das aulas remotamente.

Em meio a esse processo de preparação e pela necessidade de buscar formação continuada, tivemos a oportunidade de realizar o curso de extensão Metodologias Ativas e Tecnologias Digitais para o Trabalho Docente, ofertado pela Universidade Federal de Uberlândia (UFU) em 2020, por meio da modalidade a distância.

Diante dos desafios impostos pelo isolamento social, todos vivenciamos situações diversas, entre as quais o aumento do trabalho mental e físico por termos que ficar muitas horas em frente à tela do computador, com muitas reuniões, planejamentos e leituras; aprender a usar ferramentas tecnológicas para desenvolvermos aulas síncronas e assíncronas, além de todo o trabalho doméstico e familiar, dos filhos estudando em casa e cônjuges trabalhando em home 
office, do cuidado com membros da família pertencentes ao grupo de risco para não contraírem a COVID-19, até mesmo aprender a lidar com perdas de amigos e entes queridos vítimas dessa terrível doença.

Mesmo em contexto tão adverso, é possível dizer que as experiências vivenciadas nesse curso trouxeram valiosas contribuições teóricas e práticas para o ensino e a aprendizagem, os quais podem ser desenvolvidos por meio de metodologias ativas apoiadas em tecnologias digitais. Nesse sentido, concordamos com Bacich e Moran (2018) quando ressaltam que o processo de aprender é muito peculiar.

O curso nos proporcionou a aproximação com diversas ferramentas tecnológicas digitais que podem auxiliar a potencialização de práticas de metodologias ativas, assim como permitiu explorar diversos conceitos, estabelecer relações entre as concepções educacionais e repensar nossas práticas docentes, desafiando-nos a planejar ações a partir desses aprendizados.

No âmbito metodológico, este trabalho caracteriza-se como um relato de experiência, compreendido como a descrição de uma vivência profissional de uma de suas autoras. Assim sendo, tem-se por objetivo apresentar os resultados de uma experiência desenvolvida no componente curricular Química aplicada a serviços de alimentação, do curso Superior de Tecnologia em Gastronomia do Instituto Federal de Brasília (IFB), campus Riacho Fundo, na qual foram utilizadas metodologias ativas apoiadas em tecnologias digitais.

Diante do que se propõe, faz-se uma exposição acerca da relevância da utilização de metodologias ativas apoiadas em tecnologias digitais, com atenção à construção de espaços pedagógicos híbridos, que favorecem o repensar sobre utilização de técnicas, abordagens e métodos de ensinar e aprender Química, o que implica o redimensionamento dos saberes para a docência; logo depois, são apresentados os caminhos da pesquisa abordando a ação pedagógica objeto de análise; e, por fim, são feitas reflexões acerca da ação pedagógica sob a orientação dos eixos de análise estabelecidos.

\section{REFERENCIAL TEÓRICO}

Considerando que a experiência relatada surge a partir dos desafios propostos no curso de formação continuada Metodologias Ativas e Tecnologias Digitais para o Trabalho Docente e reconhecendo que essas metodologias não são novas e nem mesmo que existam termos específicos e únicos para identificá-las, é importante registrar que o referencial teórico utilizado neste relato de experiência está associado ao referencial básico que foi abordado no 
referido curso, embora se reconheça a existência de outras importantes referências e abordagens sobre a temática.

As metodologias ativas (MA) apresentam-se como "alternativas pedagógicas" que, entre suas características, buscam desenvolver ações que "contrastam com a abordagem pedagógica do ensino tradicional" (MORAN, 2018, p. 3). Elas combinam atividades práticas a partir de reflexões e problemas que desafiam alunos e professores a planejarem ações em busca de possíveis respostas e proposições. Nesse movimento, o diálogo, a investigação, a curiosidade, os questionamentos, as dúvidas, as sínteses, as redescobertas são elementos importantes e, por isso, rompem com o modelo transmissor e vertical de conteúdo do professor para o aluno.

As MA não são metodologias novas ou possibilidades de trabalho educativo que surgiram recentemente, pois elas existem há muito tempo, como lembrou Moran (2018). Trata-se de uma discussão que vários autores, há muitos anos, vêm propondo como possibilidade de rompimento com os modelos de educação uniformes e centrados no professor, e na qual os indivíduos podem aprender e ensinar de uma forma mais ativa. Entre esses autores, destacam-se:

Dewey (1950), Freire (1996), Ausubel et al. (1980), Rogers (1973), Piaget (2006), Vygotsky (1998) e Burner (1976), entre tantos outros que mostraram, mesmo que de forma diferente, como cada pessoa (criança ou adulto) aprende de forma ativa, a partir do contexto em que se encontra, do que lhe é significativo, relevante e próximo ao nível de competências que possui. (MORAN, 2018, p. 3).

O que torna as MA interessantes na atualidade são as possibilidades de inserção de tecnologias digitais ao processo, construindo assim espaços múltiplos, flexíveis e híbridos de aprendizagem de forma a potencializar essas metodologias, embora seja necessário ressaltar que elas não devem ser confundidas com tecnologias digitais, pois ambas podem ser utilizadas independentemente uma da outra.

Em estudo realizado por Ferrarini, Saheb e Torres (2019) sobre algumas possibilidades de metodologias ativas, os autores concluem que toda metodologia pode ser enriquecida ou não por tecnologias digitais e isso não diz necessariamente que se use metodologia ativa. Especificamente sobre as ativas, eles destacam que é importante ter claros os objetivos dos processos educacionais. Assim: 
[...] conclui-se que o uso de tecnologias digitais nos processos ensino aprendizagem não implica, necessariamente, a prática de metodologias ativas [...]. Por outro lado, denota-se claramente que as metodologias, sejam ativas ou não, podem ser potencializadas pelo uso de tecnologias digitais, conforme foi exemplificado em cada metodologia analisada. Essa aproximação é importante e necessária na atualidade em qualquer metodologia adotada, para que os processos educacionais estejam conectados ao uso de recursos tecnológicos atuais, criados ou não com fins educacionais. (FERRARINI; SAEHB; TORRES, 2019, p. 26-27).

Associando as metodologias ativas com o ensino híbrido e as tecnologias digitais, as possibilidades podem ser bem interessantes. O ensino híbrido refere-se à possibilidade de mesclar, complementar momentos de aprendizagem on-line e presencial, em torno de uma temática única, e pode ser enriquecido de atividades que envolvam tarefas individuais e coletivas que promovam debates e a produção de conhecimento em momentos a distância e presenciais. Por sua vez, está diretamente relacionado ao uso de tecnologias digitais, o que possibilita, entre outras questões, a personalização do ensino.

Mas se pensarmos no ensino remoto, em que todos estão fisicamente distantes, como o ensino híbrido pode ocorrer? Bacich e Moran (2015), embora não respondam a essa questão, trazem elementos importantes quando ressaltam que o ensino também é híbrido pela possibilidade de ensinar e aprender de forma espontânea e intencional, "porque aprendemos através de processos organizados, junto com processos abertos, informais” (p. 45).

São várias as possibilidades de se trabalhar metodologias ativas e, em especial, com o ensino híbrido e em um contexto mais geral. Moran (2015) destaca que elas requerem modelos pedagógicos mais inovadores e que cada instituição, ou mesmo professor, deve analisar cuidadosamente e decidir qual metodologia usar em determinadas situações do processo de ensino e aprendizagem, bem como pensar quais ferramentas digitais podem auxiliar a potencialização desse processo.

Ao tratar do ensino de Química, vários são os desafios e obstáculos para que os estudantes se apropriem da cultura científica. É preciso organizar o ensino de forma a promover a melhoria da aprendizagem. Mostra-se também importante tornar o processo de ensinar e aprender Química problematizador e que contribua para a formação de sujeitos ativos na sociedade, que compreendam a vida cotidiana e nela atuem tomando decisões responsáveis. Diante desses desafios, é importante se debruçar sobre o que Carvalho (2018) denomina de questões estruturantes do ensino, entre as quais está o “como ensinar”, relacionado ao problema das metodologias de ensino e da escolha dos procedimentos pedagógicos.

É muito apropriada a colocação de Moraes, Ramos e Galliazzi (2007, p. 195) de que “aprender Química se dá a partir de operações com os discursos em que estamos inseridos, no 
envolvimento em atividades concretas, coletivas", nas quais o estudante coloca em movimento o pensamento, o que exige o uso intenso da linguagem, com destaque para a fala e a escrita. Auxiliadas por Behrens (2013), podemos acrescentar que, no paradigma tradicional, termo utilizado pela autora, a linguagem oral e a escrita são utilizadas de forma que pouco contribuem para o processo de aprender e, diante disso, é imposto aos docentes o desafio de optar por caminhos que levem ao aprender.

Esse desejo de mudança de prática pedagógica se amplia quando o docente se depara com uma nova categoria do conhecimento, a digital. Dessa forma, a autora afirma que "o professor deve levar em consideração que, além da linguagem oral e da linguagem escrita, que acompanham historicamente o processo pedagógico de ensinar e aprender, é necessário considerar também a linguagem digital" (BEHRENS, 2013, p. 81, grifo da autora), a fim de romper com o conservadorismo.

\begin{abstract}
Nesse processo de incorporação, ele [o professor] precisa propor novas formas de aprender e de saber, se apropriar criticamente de novas tecnologias, buscando recursos e meios para facilitar a aprendizagem. Portanto, o professor, ao propor uma metodologia inovadora, precisa levar em consideração que a tecnologia digital possibilita o acesso ao mundo globalizado e à rede de informações disponível em todo o universo. A sala de aula passa a ser um lócus privilegiado como ponto de encontro para acessar o conhecimento, discuti-lo, depurá-lo e transformá-lo. (BEHRENS, 2013, p. 81).
\end{abstract}

Nesse universo de desafios e proposituras, é possível defender a adoção de estratégias e técnicas relacionadas às metodologias ativas e ao uso de tecnologias digitais na intenção de redimensionar técnicas, abordagens e métodos de ensinar e aprender, ultrapassando os espaços físicos dos meios escolares e favorecendo que os alunos se tornem sujeitos da aprendizagem e produtores de conhecimento.

Coadunando com o que já foi posto, trazemos Leite (2015), que, após explanar sobre o uso de tecnologias no ensino de Química, afirma que:

\footnotetext{
Não existem receitas para utilizar as tecnologias na educação, existe a necessidade de desconstrução de conceitos já estabelecidos se reconstruindo em práticas pedagógicas que levem o educador e seus educandos a mudanças de posturas no ato de aprender e de ensinar, formando uma comunidade de aprendizagem. As tecnologias, como instrumento mediador do processo de ensino e aprendizagem, tornam-se relevantes, pois os alunos se envolvem com as atividades propostas [...]. (LEITE, 2015, p. 362).
}

Diante de tudo isso, vislumbra-se como importante que professores e alunos se 
compreendam em um processo de aprender a conhecer e, para além disso, cultivem "o prazer de compreender, descobrir, construir e reconstruir o conhecimento, a curiosidade, a autonomia, a atenção" (GADOTTI, 2000, p. 9). Em se tratando da aprendizagem do professor, da aprendizagem de conhecimentos para o exercício da docência, entende-se que esta se caracteriza como um processo contínuo.

Para Ramalho e Nuñez (2014), para ser um professor profissional, é essencial o domínio de um repertório de conhecimentos coerentes com as finalidades da educação no contexto da sociedade e da escola do século XXI. Nesse contexto, emerge como importante a construção, o desenvolvimento ou a mobilização do conhecimento tecnológico e pedagógico do conteúdo ou, em inglês, Technological Pedagogical Content Knowledge (TPACK), que é um conhecimento cujo objetivo é proporcionar a compreensão adequada sobre a integração da Tecnologia de Informação e Comunicação (TIC), ou Tecnologia Digital de Informação e Comunicação (TDIC), no processo de ensino e aprendizagem, de modo que os docentes levem em consideração as relações entre tecnologias, conteúdos disciplinares e conteúdos pedagógicos e não os valorizem separadamente.

No trabalho de Rocha e Farias (2021), os autores enfatizam a necessidade de os professores de Ciências se atualizarem em práticas e técnicas metodológicas para aprimorar o seu desempenho profissional. Esses olhares e proposições para a utilização de metodologias ativas e tecnologias digitais estiveram presentes no curso Metodologias Ativas e Tecnologias Digitais para o Trabalho Docente.

Tendo em vista que o curso buscou se constituir como um espaço para a continuidade da aprendizagem, para a formação continuada de professores da educação superior e da educação básica das redes pública e privada, compreende-se que ele foi uma "ocasião de informação, reflexão, discussão e trocas que favoreceram o aprimoramento profissional" (GATTI, 2008, p. 57). Assim, a partir da experiência no referido curso, os participantes foram desafiados a pensar possibilidades de práticas com metodologias ativas baseadas em tecnologias nas suas próprias ações docentes e, nessa perspectiva, é que se apresentam os resultados ora socializados neste relato de experiência.

\section{CAMINHOS DA PESQUISA}

Este estudo relata uma experiência desenvolvida na disciplina de Química aplicada a serviços de alimentação no Instituto Federal de Brasília, campus Riacho Fundo (PC, 2017). 
Uma das autoras deste trabalho foi pesquisadora e participante do referido componente disciplinar e promoveu experiências com metodologias ativas, as quais foram analisadas à luz do referencial teórico que apoiou as discussões e práticas realizadas pelas autoras a partir do curso Metodologias Ativas e Tecnologias Digitais para o Trabalho Docente (MATDICs/UFU, 2020).

O componente curricular Química aplicada a serviços de alimentação faz parte da matriz curricular do curso Superior de Tecnologia em Gastronomia, oferecido pelo IFB, campus Riacho Fundo. Conforme o Plano de Curso (PC, 2017), as bases tecnológicas desse componente são: aspectos químicos presentes nos alimentos; transformações físico-químicas dos alimentos; procedimentos de alteração de textura, sabor e cor dos alimentos. Ofertado no primeiro semestre do referido curso, com uma carga horária de 40 horas, no ano de 2020, tal componente iniciouse em março e teve apenas três encontros presenciais, pois, em seguida, o calendário acadêmico foi suspenso devido ao isolamento social.

As aulas retornaram em agosto do mesmo ano, mas na forma de ensino remoto, utilizando tecnologias digitais como suporte. Dessa forma, foi necessário reinventar as formas de ensinar e de aprender, bem como os professores e alunos tiveram que aprender a usar as tecnologias digitais para se comunicarem, produzirem conhecimento e desenvolverem habilidades. Neste novo cenário, o componente curricular Química aplicada a serviços de alimentação precisou ser reestruturado e, nesse processo de transição do ensino presencial para o ensino remoto, exigiu novos saberes docentes.

Na ocasião, a professora desse componente curricular, além de ações de formação na sua própria instituição, buscou outras possibilidades de formação continuada para auxiliar o processo de planejamento e desenvolvimento do componente curricular no formato remoto. Entre essas possibilidades, realizou o mencionado curso de Metodologias Ativas e Tecnologias Digitais para o Trabalho Docente (MATDICs/UFU, 2020), o qual oportunizou o encontro das pesquisadoras que, em processo colaborativo, propuseram este estudo.

O Quadro 1 apresenta os objetivos de aprendizagem de cada roteiro do componente curricular, cujas atividades abordavam o conteúdo científico de interesse. O componente foi apresentado a partir de um vídeo interativo utilizando-se a ferramenta digital Powtoon, a qual é usada para criar apresentações e vídeos animados de explicação de conteúdos. 


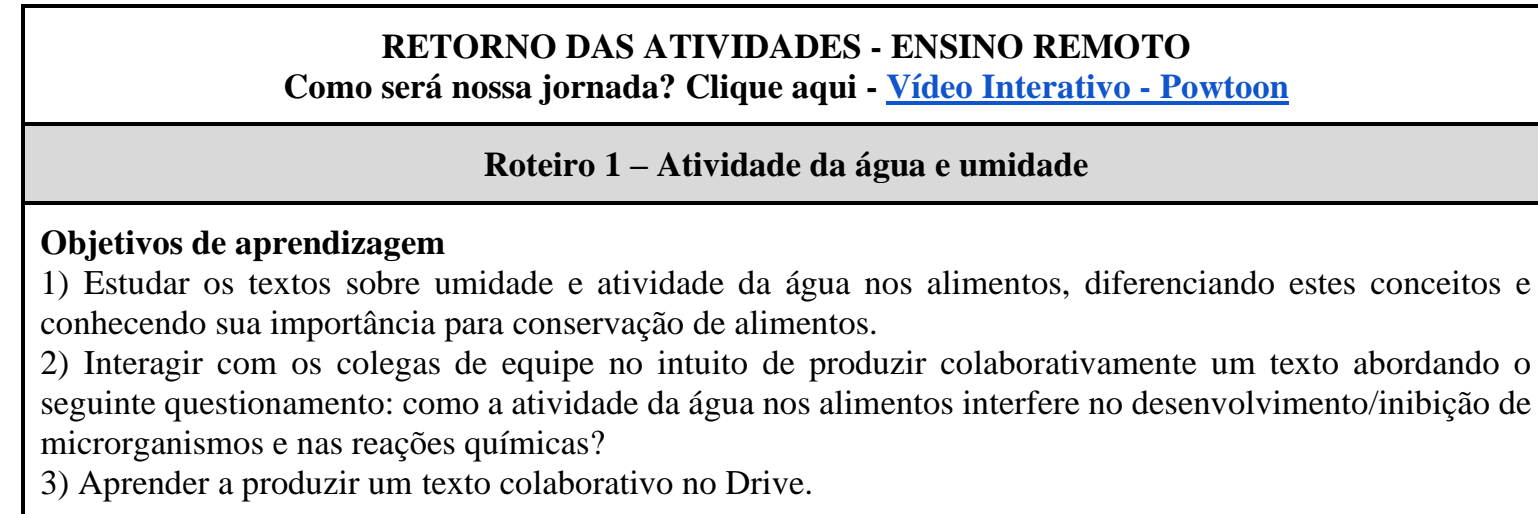

Roteiro 2 - Proteínas - ovos

\section{Objetivos de aprendizagem}

1) Conhecer a composição, o valor nutricional e a constituição dos ovos.

2) Conhecer as principais proteínas presentes nos ovos e as funções que desempenham.

3) Produzir um material que explique os experimentos do Juca.

Link do podcast: https://anchor.fm/karlaamancio/episodes/Juca--o-aventureiro-ei238u

\section{Roteiro 3 - Frutas e vitaminas}

\section{Objetivos de aprendizagem}

- Diferenciar vitaminas lipossolúveis e hidrossolúveis.

- Identificar quais características organolépticas são alteradas nas frutas durante o processo de amadurecimento.

- Diferenciar frutas climatérias e não climatérias e relacionar aos processos de compra e armazenamento.

\section{Roteiro 4 - Produção de uma sobremesa com frutas}

\section{Objetivos de aprendizagem}

- Relacionar os conteúdos discutidos na semana 3 com relação aos processos de aquisição, armazenamento, pré-preparo e cocção de frutas com a produção de uma sobremesa de frutas, ou seja, relacionar a teoria e a prática; pesquisar a origem da sobremesa.

\section{Roteiro 5 - Carboidratos}

\section{Objetivos de aprendizagem}

- Conhecer as propriedades físico-químicas dos mono, oligo e polissacarídeos.

- Entender a importância dessas propriedades para a gastronomia.

- Produzir uma história em quadrinhos sobre a temática carboidratos.

Quadro 1: Planejamento do componente curricular Fonte: Elaborado pelas autoras (2020).

Estabelecendo um paralelo com o curso Metodologias Ativas e Tecnologias Digitais para o Trabalho Docente (MATDICs/UFU, 2020), que nos desafiou à experiência relatada, ressaltamos que as ações de ensino desenvolvidas estão apresentadas a partir de cinco práticas com metodologias ativas. 


\section{ANÁLISE E RESULTADOS}

A partir do planejamento do componente curricular, organizamos a apresentação dos dados dessa experiência a partir de cinco metodologias, entre elas: storytelling, storytelling e resolução de problemas, ensino híbrido/sala de aula invertida, aprendizagem em pares e aprendizagem maker.

\subsection{Storytelling}

A primeira atividade elaborada pela professora foi um vídeo de boas-vindas ao ensino remoto, utilizando a ferramenta digital Powtoon. Nesse vídeo interativo, a professora utilizou a metodologia ativa storytelling, uma forma de contar uma história em que os recursos audiovisuais são utilizados juntamente com as palavras. Para Marques, Miranda e Mamede (2020, p. 170), “a contação de histórias, no contexto acadêmico, consiste em uma técnica de captar a atenção das pessoas por meio do relato de um acontecimento fictício ou real, com o objetivo de ensinar".

Nesse sentido, o vídeo interativo apresentou como seria a jornada do componente curricular Química aplicada a serviços de alimentação durante o ensino remoto. No vídeo, foi apresentado o plano da disciplina, destacando elementos como a carga horária total do componente curricular, a carga horária cumprida antes do isolamento social e a carga horária restante, enfatizando que todos estavam aprendendo a usar as tecnologias digitais. Ainda no vídeo, a professora afirmou que o ambiente virtual de aprendizagem (AVA) utilizado seria o Google Sala de Aula e que os encontros síncronos ocorreriam no Google Meet.

No Roteiro 5, foi exigida dos alunos a criação de uma história em quadrinhos sobre o tema carboidratos. Inicialmente os alunos leram os textos disponibilizados pela professora e depois, em grupos e individualmente, criaram quatorze histórias em quadrinhos. A Figura 1 apresenta parte de uma história em quadrinhos elaborada pela aluna P. Para acessar a história em quadrinhos completa, acesse aqui o hiperlink. 


\section{REAMEC \\ REVISTA DA REDE AMAZÓNICA DE EDUCAÇĊO EMCIẼNCLAS MATEMATICA}
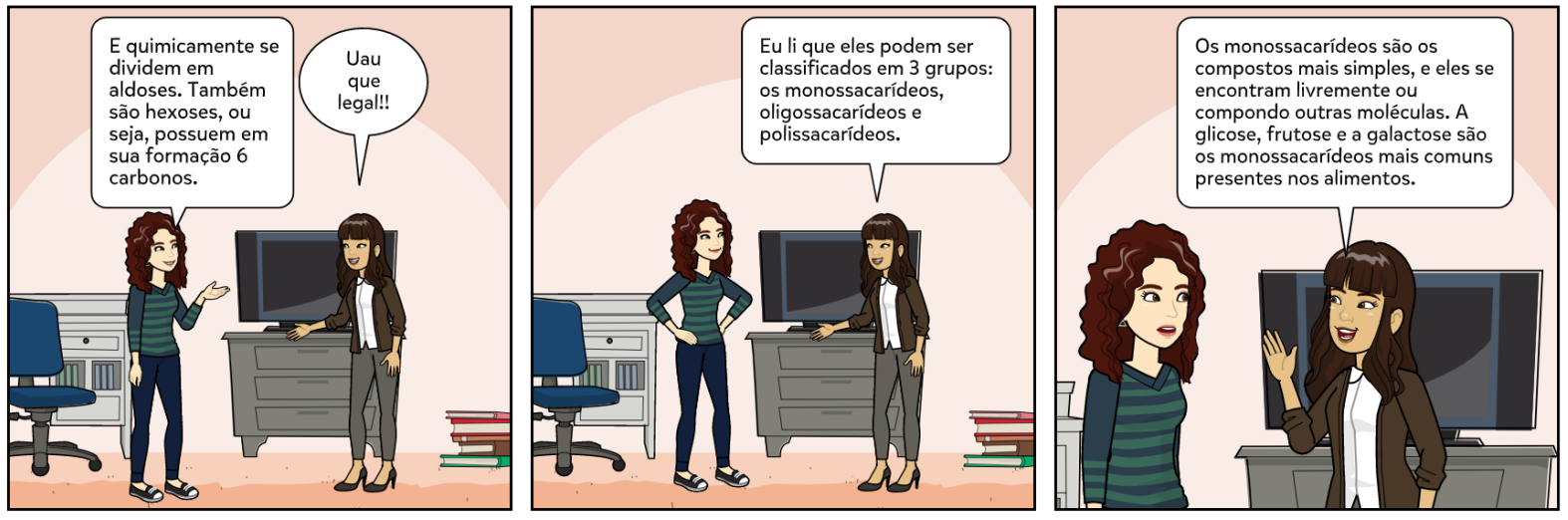

Figura 1- Print da história em quadrinhos produzida pela aluna $\mathrm{P}$. Fonte: Elaborada pela aluna P.

Nessa atividade, verificamos que a aluna falou sobre a classificação dos carboidratos (monossacarídeos, oligossacarídeos e polissacarídeos), a função dos carboidratos nos alimentos e para nosso organismo, além de destacar o amido, o carboidrato usado para promover uma textura gelatinosa. Diante dessa história em quadrinhos, concordamos com Moran $(2018$, p. 21) de que "as narrativas são elementos poderosos de motivação e produção de conhecimento".

\subsection{Storytelling e resolução de problemas}

Para as atividades que compõem o Roteiro 2, a professora produziu o podcast "Juca, o aventureiro". Os podcasts são arquivos de áudio transmitidos via internet que podem ser baixados ou reproduzidos on-line. Para a produção do podcast do Juca, foi utilizada a ferramenta digital Anchor, que é uma plataforma para iniciantes, gratuita e amigável, para a criação de podcast. A professora partiu de uma estória problema para que os alunos do curso Superior de Tecnologia em Gastronomia pensassem alternativas que ajudassem o Juca, personagem da estória, a compreender o que aconteceu com os experimentos dele.

Ao produzir o podcast "Juca, o aventureiro", houve a intenção pedagógica de estruturar a atividade com a finalidade de resolução de problemas. Assim, nesse podcast, a estória propõe problemas relativos à formação de claras em neve usando diferentes substâncias e utensílios (sal, açúcar, gordura, água e cobre). Os experimentos do Juca apresentam questões provocativas relacionadas à atuação do profissional de gastronomia.

A partir dessa estória e da proposição dos problemas, os alunos foram desafiados a propor respostas/alternativas práticas, fazendo reflexões sobre o conteúdo teórico da disciplina. Os relatos dos alunos mostram coerência conceitual nas explicações sobre os experimentos do Juca, demonstrando seu envolvimento com os conceitos da disciplina. A resolução de 
problemas instigou os alunos de Gastronomia a buscarem explicações para questões relativas à sua futura profissão. Nessa perspectiva, Moran (2018) ressalta que "o foco na aprendizagem baseada em problemas é a pesquisa de diversas causas possíveis para um problema” (p. 16).

\subsection{Ensino híbrido/sala de aula invertida}

Para a discussão de cada tema, foram disponibilizados textos e/ou videoaulas para que os alunos estudassem previamente e pudessem discutir e tirar dúvidas nas aulas seguintes. Essa ação pedagógica está pautada na ideia da sala de aula invertida, a qual se caracteriza como uma estratégia ativa e um modelo híbrido em que o conhecimento básico fica por conta do aluno, com a curadoria do professor; e nos estágios mais avançados, há a interferência do professor e um forte componente grupal. O importante nesse tipo de estratégia é engajar o aluno em questionamentos e resolução de problemas, oportunizando a revisão, ampliação e aplicação do que foi aprendido (MORAN, 2018).

Em todos os roteiros, identificamos que a professora utilizou a metodologia de sala de aula invertida, pois ela orientava que os alunos tivessem um primeiro contato com o tema a partir da leitura de textos e videoaulas relacionados aos temas que seriam trabalhados em cada roteiro. Nas aulas posteriores e já contando com o acesso prévio ao conteúdo, os alunos eram desafiados a explorar seus conhecimentos a partir das atividades propostas, a pensar nos conteúdos a partir de leituras, complementados por vídeos e, ao mesmo tempo, a conseguir relacionar esses conhecimentos nas atividades realizadas virtualmente.

Na gênese da sala de aula invertida, como proposto por Bergmann e Sams (2018), utiliza-se principalmente de vídeo como material para estudo prévio por parte dos alunos, e do tempo em sala de aula para ajudá-los na melhor compreensão dos conceitos. Em geral, isto ainda é comum: os alunos assistem a vídeos ou animações e leem textos; porém há outras formas de inverter o processo de aprendizagem, tal como a utilização de projetos, pesquisas e produções dos alunos e, posteriormente, o aprofundamento pelo professor (MORAN, 2018).

\subsection{Aprendizagem em pares}

No Roteiro 1, como pode ser observado anteriormente no Quadro 1, foi solicitada aos alunos a elaboração de um texto colaborativo. Anteriormente a essa produção, os alunos estudaram os textos sobre umidade e atividade da água nos alimentos. 
Para isso, foi solicitado o uso do Google Documentos como ferramenta digital e colaborativa. A atividade foi apresentada aos alunos na aula síncrona e, após explanação e orientações, dois alunos ressaltaram que o momento síncrono entre os integrantes do grupo teria sido fundamental para realizar o trabalho e que a incompatibilidade de horários foi o empecilho para o desenvolvimento do texto colaborativo. Outro ponto apontado por três estudantes foi a não familiaridade com as tecnologias digitais, neste caso, o Google Documentos, além do fato de ser aquela a primeira semana deles naquele formato de aula, o que os deixava assustados, como apontaram os alunos A e F. Estes relatos foram transcritos das videoaulas síncronas:

A-1-29:32 ${ }^{1}$ a gente ainda está assustado, como eu falei ontem com outra professora, com tantas novidades e meio que desesperados, igual nossa colega falou [...]

F-1-32:42 eu também tô espantado com isso, como nada é palpável, é concreto, acho que dificulta mais $[\ldots]$ mas nós somos adaptáveis $[\ldots]$

Diante dessas dificuldades iniciais, o texto colaborativo foi possível apenas para dois grupos, os quais tinham tempo para se "encontrarem" e tinham disposição para aprender essas novas ferramentas. Os demais alunos realizaram a atividade individualmente, pois ainda naquele momento não possuíam habilidades para o trabalho colaborativo usando as ferramentas digitais.

Os textos elaborados foram avaliados seguindo os critérios preestabelecidos e as devolutivas foram feitas na plataforma AVA. Ressaltamos que vários alunos tiveram dificuldades em postar essa atividade, ficaram inseguros em utilizar o AVA e foi necessário acompanhar e orientar individualmente as postagens.

Além dessas, os alunos também tiveram dificuldades com os e-mails institucionais, pois era necessária sua utilização para ter acesso ao AVA e, consequentemente, aos textos, às videoaulas e às tarefas. Essas dificuldades foram sanadas conforme os alunos prosseguiram nas atividades e assim foram se familiarizando tanto com o ambiente quanto com as ferramentas.

O Google Documentos possibilita que sejam elaborados textos de forma colaborativa na aprendizagem em pares, também conhecida por Peer Instruction. Assim como em outras metodologias ativas, o professor, que é um mediador, passa a fazer interação entre os alunos em sala de aula; e estes, por sua vez, ensinam ao outro a partir da dificuldade encontrada em cada problema proposto, permitindo que haja interação entre os escritores, sem a necessidade

\footnotetext{
${ }^{1}$ Para preservar o anonimato dos alunos nas transcrições, utilizamos o símbolo A-1-29:32, que representa o aluno A, na primeira semana de aula síncrona, no turno da fala em 29 minutos e 32 segundos da videoaula da semana 1. 
de que estejam todos no mesmo espaço físico e trabalhando ao mesmo tempo. É importante que os alunos tenham mais familiaridade com a ferramenta, inclusive que ressignifiquem a ideia de espaço e tempo de trabalho colaborativo ao terem seu trabalho auxiliado por tecnologias digitais, percebendo as possibilidades que estas oferecem para a construção de um texto coletivo.

Ao se apropriarem do modo de usar, é preciso cultivar a percepção das possibilidades de diálogo favorecidas pela ferramenta. É justamente o diálogo, apoiado nas experiências vividas, nas leituras já realizadas e nas atividades já desenvolvidas, e a cooperação que auxiliam a ampliação do conhecimento dos envolvidos. "Os objetivos básicos da Peer Instruction são: explorar a interação entre estudantes durante as aulas expositivas e focar a atenção dos estudantes nos conceitos que servem de fundamento" (MAZUR, 2015, p. 10).

\subsection{Aprendizagem maker}

No Roteiro 4, foi solicitada aos alunos a produção de uma sobremesa com frutas. Além de postar a foto do prato, os alunos teriam que escrever a receita e sua origem. O feedback foi dado por uma professora da Gastronomia. Nessa metodologia, identificamos elementos da aprendizagem maker.

A experiência do fazer (maker), associada à reflexão apoiada na teoria, permitiu aos alunos da Gastronomia dar significado à relação entre teoria e prática, e a contribuição de uma pessoa mais experiente (professora da Gastronomia) possibilitou uma reflexão sobre a importância de se comunicar bem através de seus textos e produções, não só para fortalecer as pesquisas na área gastronômica, mas também para influenciar experiências posteriores.

No ambiente educacional, a aprendizagem maker está relacionada ao faça você mesmo. Há algumas correntes que afirmam que, para a aprendizagem ser maker, "o fazer tem que ter uma parte digital, e outra corrente afirma que basta você construir algo significativo como resultado da resolução de problemas, sem necessariamente fazer uso da tecnologia, utilizando materiais que tenha ao alcance das mãos" (SILVA; SILVA; SILVA, 2018, p. 3).

$\mathrm{Na}$ aprendizagem maker, os alunos colocam a mão na massa (experimentação) e, dessa forma, compreendem e aperfeiçoam os conhecimentos recebidos nas aulas síncronas. Aqui os alunos foram desafiados a dar significado aos conteúdos teóricos sobre os processos de aquisição, armazenamento, pré-preparo e cocção de frutas com a produção de uma sobremesa de frutas. Para Blinkstein (2016), o foco da aprendizagem maker está no processo e não no 
produto, pois é importante que o professor preste atenção ao processo, observe a criatividade, a aprendizagem, "a postura empreendedora e o desenvolvimento da capacidade de inovação, que são aspectos importantes na formação de cada indivíduo" (SILVA; SILVA; SILVA, 2018, p. 2).

\section{CONSIDERAÇÕES}

Este trabalho teve como objetivo apresentar os resultados de uma experiência desenvolvida no componente curricular Química aplicada a serviços de alimentação do curso Superior de Tecnologia em Gastronomia do Instituto Federal de Brasília, campus Riacho Fundo (PC, 2017), na qual foram utilizadas metodologias ativas apoiadas em tecnologias digitais. Para uma abordagem metodológica de apresentação, optamos pelo relato de experiência.

Os resultados dessa experiência apontam que houve uma apropriação metodológica por parte da professora, o que é exemplificado pelo planejamento dos roteiros de aprendizagem, conforme proposto a partir das metodologias ativas: storytelling, aulas invertidas, resolução de problemas e aprendizagem maker. Por sua vez, as tecnologias digitais que apoiaram essas metodologias, como a Powtoon, o Google Documentos, o podcast (Anchor) e o Google Meet, auxiliaram a sua potencialização apesar das dificuldades surgidas.

Os dados evidenciam que a participação da professora no curso de Metodologias Ativas e Tecnologias Digitais para o Trabalho Docente constitui-se como uma experiência importante em sua formação, pois a auxiliou a mobilizar aspectos necessários para suas práticas pedagógicas, possibilitando-lhe elementos teóricos e práticos para que agisse de forma mais assertiva.

Pelas atividades propostas nas cinco metodologias ativas apoiadas por tecnologias digitais, percebe-se que alguns alunos foram aos poucos se relacionando com as propostas, interagindo com elas e com o grupo, colaborando com outros colegas e desenvolvendo as potencialidades de uma aprendizagem mais ativa e autônoma, embora ainda não compreendessem essas possibilidades e apresentassem dificuldades de acesso às ferramentas.

Assim como a professora que atuou diretamente nessa experiência, nós que apenas participamos do curso na condição de alunos e professores também ressaltamos que o referido curso de extensão alcançou seus objetivos no sentido de possibilitar um espaço de formação continuada em que tivemos acesso às discussões iniciais e a materiais de estudos e leituras complementares para aprofundar os conhecimentos sobre metodologias ativas e tecnologias 


\section{REAMEC

digitais.

Nossa expectativa é que essa primeira experiência/vivência tanto da professora quanto dos alunos com metodologias ativas apoiadas em tecnologias digitais promova várias outras oportunidades e momentos de cocriação com seus alunos, e contribua para mudanças de práticas mais significativas.

\section{REFERÊNCIAS}

BEHRENS, Marilda Aparecida. Projetos de aprendizagem colaborativa num paradigma emergente. In: MORAN, José Manuel; MASETTO, Marcos T.; BEHRENS, Marilda Aparecida. Novas tecnologias e mediação pedagógica. 21. ed. rev. e atual. Campinas, SP: Papirus, 2013. p. 73-140.

BACICH, Lilian. Formação continuada de professores para o uso de metodologias ativas. In: BABICH, Lilian; MORAN, José (orgs.). Metodologias ativas para uma educação inovadora. Porto Alegre: Penso, 2018. p. 129-152.

BACICH, Lilian; MORAN, José. Aprender e ensinar com foco na educação híbrida. Revista Pátio, n. 25, junho, p. 45-47, 2015. Disponível em: http://www2.eca.usp.br/moran/wpcontent/uploads/2015/07/hibrida.pdf. Acesso em: 21 nov. 2020.

BERGMANN, Jonathan; SAMS, Aaron. Sala de aula invertida: uma metodologia ativa de aprendizagem. Tradução Afonso Celso da Cunha Serra. 1. ed. reimpr. Rio de Janeiro: LTC, 2018.

BLINKSTEIN, Paulo. Educação mão na massa. [Entrevista para o site Porvir]. Conferência FabLearn Brasil. São Paulo, USP - Universidade de São Paulo, set. 2016. Disponível em: http://porvir.org/especiais/maonamassa/?gclid=Cj0KCQjwnNvaBRCmARIsAOfZq3osMD1faI72 ktI-caMXwySkVQsMnq3EBpDwHCJOg5Fa187ZpY-kk8aApqIEALw_wcB. Acesso em: 04 fev. 2021.

CARVALHO, Anna Maria Pessoa de. Critérios estruturantes para o ensino de ciências. In: CARVALHO, Anna Maria Pessoa de (org.). Ensino de ciências: unindo a pesquisa e a prática. São Paulo: Cengage Learning, 2009. p. 1-17.

FERRARINI Rosilei, SAHEB Daniele, TORRES, Patricia Lupion. Metodologias ativas e tecnologias digitais: aproximações e distinções. Revista Educação em Questão, Natal, v. 57, n. 52, p. 1-30, e- 15762, abr./jun. 2019. Disponível em:

https://periodicos.ufrn.br/educacaoemquestao/article/view/15762. Acesso em: 28 maio 2021.

GADOTTI, Moacir. Perspectivas atuais da educação. São Paulo em Perspectiva, v. 14, n. 2, p. 3-9, 2000.

GATTI, Bernadete Angelina. Análise das políticas públicas para a formação continuada no Brasil, na última década. Revista Brasileira de Educação, Campinas, SP, v. 13, n. 37, p. 57 - 
186, jan./abr. 2008. Disponível em: https://www.scielo.br/pdf/rbedu/v13n37/06.pdf. Acesso em: 12 out. 2020.

LEITE, Bruno Silva. Tecnologias no ensino de química: teoria e prática na formação docente. 1. ed. Curitiba: Appris, 2015.

MARQUES, Alessandra Vieira Cunha; MIRANDA, Gilberto José; MAMEDE, Samuel de Paiva Naves. Storytelling: aprendizado de longo prazo. In: LEAL, Edvalda Araújo; MIRANDA, Gilberto José; CASA NOVA, Silvia Pereira de Castro (org.). Revolucionando a sala de aula: como envolver o estudante aplicando as técnicas de metodologias ativas de aprendizagem. São Paulo: Atlas, 2017. p. 169-185.

MATDICs/UFU. Projeto do Metodologias Ativas e Tecnologias Digitais para o Trabalho Docente. Instituto de Ciências Humanas do Pontal (ICHPO), Programa Rede de Extensão UFU em Casa. 25/05/2020 a 11/09/2020, carga horária de 80 horas.

MAZUR, Eric. Peer Instruction - a revolução da aprendizagem ativa. Porto Alegre: Penso, 2015.

MISHRA, Punya; KOEHLER, Matthew J. Technological pedagogical content knowledge: a framework for teacher knowledge. Teachers College Record, v. 108, n. 6, p. 1017-1054, jun. 2006.

MORAES, Roque; RAMOS, Maurivan Guntzel. Aprender química: promovendo excursões em discursos de química. In: ZANON, Lenir Basso; MALDANER, Otavio Aloisio (orgs.). Fundamentos e propostas de ensino de química para a educação básica no Brasil. Ijuí: Ed. Unijuí, 2007. p. 191-209.

MORAN, José. Educação híbrida: um conceito-chave para a educação hoje. In: BABICH, Lilian; TANZI NETO, Adolfo; TREVISANI, Fernando de Mello. Ensino híbrido: personalização e tecnologia na educação. 2. reimpressão. Porto Alegre: Penso, 2015. p. 27-45.

MORAN, José. Mudando a educação com metodologias ativas. In: SOUZA, Carlos Alberto de; MORALES, Ofelia Elisa (org.). Convergências Midiáticas, Educação e Cidadania: aproximações jovens. Ponta Grossa: UEPG/PROEX, 2015. p. 15-33. Disponível em: http://www2.eca.usp.br/moran/wp-content/uploads/2013/12/mudando_moran.pdf. Acesso em: 21 nov. 2020.

MORAN, José. Metodologias ativas para uma aprendizagem mais profunda. In: BABICH, Lilian; MORAN, José (orgs.). Metodologias ativas para uma educação inovadora. Porto Alegre: Penso, 2018. p. 1-25.

PLANO de Curso do Curso Superior de Tecnologia em Gastronomia do IFB - Campus Riacho Fundo. Brasília, DF. 2017.

RAMALHO, Betânia Leite; NUÑEZ, Isauro Beltrán. Aprendizagem da docência, formação e desenvolvimento profissional: trilogia da profissionalização docente. In: RAMALHO, Betânia Leite; NUÑEZ, Isauro Beltrán (orgs.). Formação, representações e saberes docentes: elementos para se pensar a profissionalização dos professores. Campinas, SP: Mercado das 
Letras; Natal, RN: UFRN, 2014. p. 17-37.

ROCHA, Carlos José Trindade; FARIAS, Sidilene Aquino. Metodologias ativas de aprendizagem possíveis ao ensino de ciências e matemática. REAMEC - Rede Amazônica de Educação em Ciências e Matemática, [S. 1.], v. 8, n. 2, p. 69-87, 2020. DOI:

10.26571/reamec.v8i2.9422. Disponível em: https://periodicoscientificos.ufmt.br/ojs/index.php/reamec/article/view/9422. Acesso em: 1 jun. 2021.

SILVA, Maria Aparecida Francelino; SILVA, Jaelson Dantas; SILVA, Janaína Salustiano. Cultura maker e educação para o século XXI: relato da aprendizagem mão na massa no $6^{\circ}$ ano do ensino fundamental/integral do Sesc Ler Goiana. In: $16^{\circ}$ CONGRESSO INTERNACIONAL DE TECNOLOGIA NA EDUCAÇÃO. Brasil, Recife, set. 2018. Anais [...] Acesso em: 17 out. 2020.

\section{APÊNDICE 1}

\section{AGRADECIMENTOS}

Agradecemos à professora de Gastronomia Juliana de Andrade Rocha Gonçalves pelo apoio em uma das atividades.

\section{CONTRIBUIÇÕES DE AUTORIA}

Resumo: Karla Amâncio Pinto Field's, Kátia Dias Ferreira Ribeiro, Raquel Aparecida Souza

Abstract: Beatriz Ribeiro Ferreira

Resumen: Alessandra Silva de Sousa

Introdução: Karla Amâncio Pinto Field's, Kátia Dias Ferreira Ribeiro, Raquel Aparecida Souza

Referencial teórico: Karla Amâncio Pinto Field's, Kátia Dias Ferreira Ribeiro, Raquel Aparecida Souza

Análise de dados: Karla Amâncio Pinto Field's, Kátia Dias Ferreira Ribeiro, Raquel Aparecida Souza

Discussão dos resultados: Karla Amâncio Pinto Field's, Kátia Dias Ferreira Ribeiro, Raquel Aparecida Souza

Conclusão e considerações finais: Karla Amâncio Pinto Field's, Kátia Dias Ferreira Ribeiro, Raquel Aparecida Souza

Referências: Karla Amâncio Pinto Field's, Kátia Dias Ferreira Ribeiro, Raquel Aparecida Souza

Revisão do manuscrito: Simone Souza Cunha da Silva

Aprovação da versão final publicada: Karla Amâncio Pinto Field's, Kátia Dias Ferreira Ribeiro, Raquel Aparecida Souza

\section{CONFLITOS DE INTERESSE}

Declarar não haver nenhum conflito de interesse. Texto sugestivo: Os autores declararam não haver nenhum conflito de interesse de ordem pessoal, comercial, acadêmico, político e financeiro referente a este manuscrito.

\section{DISPONIBILIDADE DE DADOS DE PESQUISA}

O conjunto de dados que dá suporte aos resultados da pesquisa foi publicado no próprio artigo.

\section{CONSENTIMENTO DE USO DE IMAGEM}

Não se aplica.

\section{COMO CITAR ABNT}

FIELD’S, Karla Amâncio Pinto. RIBEIRO, Kátia Dias Ferreira. SOUZA, Raquel Aparecida. UTILIZAÇÃO DE METODOLOGIAS ATIVAS APOIADAS EM TECNOLOGIAS DIGITAIS PARA O ENSINO DE QUÍMICA: UM RELATO DE EXPERIÊNCIA. REAMEC - Rede Amazônica de Educação em Ciências e Matemática. Cuiabá, v. 9, n. 2, e21052, maio-agosto, 2021. http://dx.doi.org/10.26571/reamec.v9i2.11890. 
COMO CITAR APA

FIELD'S, K. A. P. RIBEIRO, K. D. F. SOUZA, R. A. (2021). UTILIZAÇÃO DE METODOLOGIAS ATIVAS APOIADAS EM TECNOLOGIAS DIGITAIS PARA O ENSINO DE QUÍMICA: UM RELATO DE EXPERIÊNCIA. REAMEC - Rede Amazônica de Educação em Ciências e Matemática, 9 (2), e21052. http://dx.doi.org/10.26571/reamec.v9i2.11890.

\section{LICENÇA DE USO}

Licenciado sob a Licença Creative Commons Attribution-NonCommercial 4.0 International (CC BY-NC 4.0). Esta licença permite compartilhar, copiar, redistribuir o manuscrito em qualquer meio ou formato. Além disso, permite adaptar, remixar, transformar e construir sobre o material, desde que seja atribuído o devido crédito de autoria e publicação inicial neste periódico.

\section{DIREITOS AUTORAIS}

Os direitos autorais são mantidos pelos autores, os quais concedem à Revista REAMEC - Rede Amazônica de Educação em Ciências e Matemática - os direitos exclusivos de primeira publicação. Os autores não serão remunerados pela publicação de trabalhos neste periódico. Os autores têm autorização para assumir contratos adicionais separadamente, para distribuição não exclusiva da versão do trabalho publicada neste periódico.

\section{PUBLISHER}

Universidade Federal de Mato Grosso. Programa de Pós-graduação em Educação em Ciências e Matemática (PPGECEM) da Rede Amazônica de Educação em Ciências e Matemática (REAMEC). Publicação no Portal de Periódicos UFMT. As ideias expressadas neste artigo são de responsabilidade de seus autores, não representando, necessariamente, a opinião dos editores ou da referida universidade.

\section{EDITOR}

Marcel Thiago Damasceno Ribeiro

\section{HISTÓRICO}

Submetido: 22 de fevereiro de 2021.

Aprovado: 24 de maio de 2021.

Publicado: 22 de agosto de 2021. 